\title{
Transmastoid Repair of Superior Semicircular Canal Dehiscence
}

\author{
Yi Chen Zhao ${ }^{1}$ Thomas Somers $^{2}$ Joost van Dinther ${ }^{2}$ Robby Vanspauwen ${ }^{2}$ Jacob Husseman ${ }^{1}$ \\ Robert Briggs ${ }^{1}$ \\ ${ }^{1}$ Department of Otolaryngology, Royal Victorian Eye and Ear Hospital, \\ Melbourne, Victoria, Australia \\ 2 ENT Department, European Institute for Otorhinolaryngology, \\ Sint-Augustinus Hospital, Antwerp, Belgium \\ Address for correspondence and reprint requests $Y i$ Chen Zhao, \\ M.B.B.S., Ph.D., Department of Otolaryngology, The University \\ of Melbourne, Royal Victorian Eye and Ear Hospital, \\ 32 Gisborne Street, East Melbourne, Victoria 3002, Australia \\ (e-mail: yczhao188@yahoo.com). \\ J Neurol Surg B 2012;73:225-229.
}

Superior semicircular canal (Sup SC) dehiscence syndrome (SSCDS) is a recently recognized syndrome. It consists of a variety of auditory symptoms including autophony, hyperacusis, tinnitus, as well as vestibular symptoms of soundinduced and pressure-induced vertigo. These symptoms arise as a result of the third mobile window effect from a dehiscence of the Sup SC. Since its first description in $1998,{ }^{1}$ the surgical management of this condition has been a middle cranial fossa, extradural approach to resurface the Sup SC. ${ }^{2,3}$ While this approach is effective in treating the symptoms, it is not without potential complications. It has been demonstrated that plugging of the dehiscent canal provides more effective symptom control than resurfacing without increased sensorineural hearing loss. While resurfacing of the Sup SC does require an extradural middle cranial fossa approach, plugging of the canal can be achieved via a transmastoid approach avoiding the need for a craniotomy and temporal lobe retraction. ${ }^{4-6}$ In view of this, our practice has changed received

September 9, 2010

accepted

December 7, 2011

published online

May 17, 2012
Copyright $\odot 2012$ by Thieme Medical Publishers, Inc., 333 Seventh Avenue, New York, NY 10001, USA.

Tel: +1(212) 584-4662.
DOI http://dx.doi.org/ 10.1055/s-0032-1312713. ISSN 2193-6331. 
and a transmastoid approach is routinely used for Sup SC plugging in patients with adequate temporal bone pneumatization.

The aim of this study was to review the efficacy of the transmastoid approach for plugging of Sup SC dehiscence focusing specifically on symptom control and hearing preservation.

\section{Material and Methods}

A retrospective chart review of all patients who underwent transmastoid approach to Sup SC occlusion performed between 2008 and 2011 at two tertiary otology institutions (the Royal Victorian Eye and Ear Hospital, Melbourne, Australia and Sint-Augustinus Hospital, Antwerp, Belgium) was performed.

\section{Surgical Technique}

A transmastoid approach to the Sup SC was employed in all patients. A C-shaped postauricular incision was made and temporalis fascia harvested. Periosteum was elevated to expose the mastoid cortex and a cortical mastoidectomy was performed with the identification of the tegmen, sigmoid sinus, lateral semicircular canal, and mastoid antrum. The labyrinth was skeletonized and the Sup SC was then blue lined beneath the middle fossa dura (i.e., the dehiscent portion of the canal was blue lined from posteriorly) using a $2 \mathrm{~mm}$ diamond burr ( $\mathbf{- F i g . ~ 1 ) . ~ A ~ s i n g l e ~ f e n e s t r a t i o n ~ w a s ~ o p e n e d ~ a t ~}$ the apex of the Sup SC arch laterally using a 90-degree hook (-Fig. 2). Fascia strips were used to completely occlude the canal lumen by plugging the canal toward the ampulla and toward the common crus ( - Fig. 3). Finally, bone pâté mixed with Tisseel (Fibrin Sealant, Baxter Healthcare Corporation $($, Deerfield, IL, USA) was used to further plug the canal and seal the point of fenestration (-Fig. 4). The wound was closed in layers with absorbable sutures and mastoid compression dressing applied.

In this case series, three cases had a single fenestration at the site of Sup SC dehiscence while seven cases performed in Belgium had two separate fenestrations made. The anterior

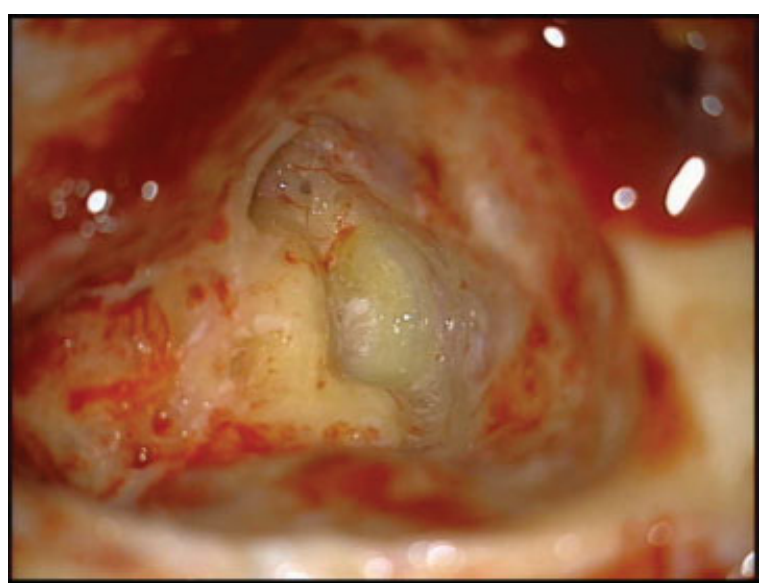

Figure 1 Intraoperative photo 1 demonstrating the blue lined the superior semicircular canal.

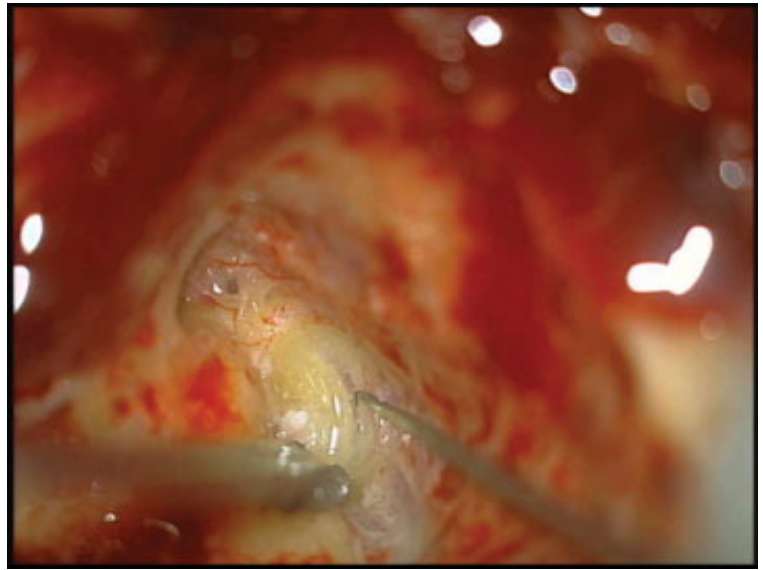

Figure 2 Intraoperative photo of the superior semicircular canal opened with 90-degree hook.

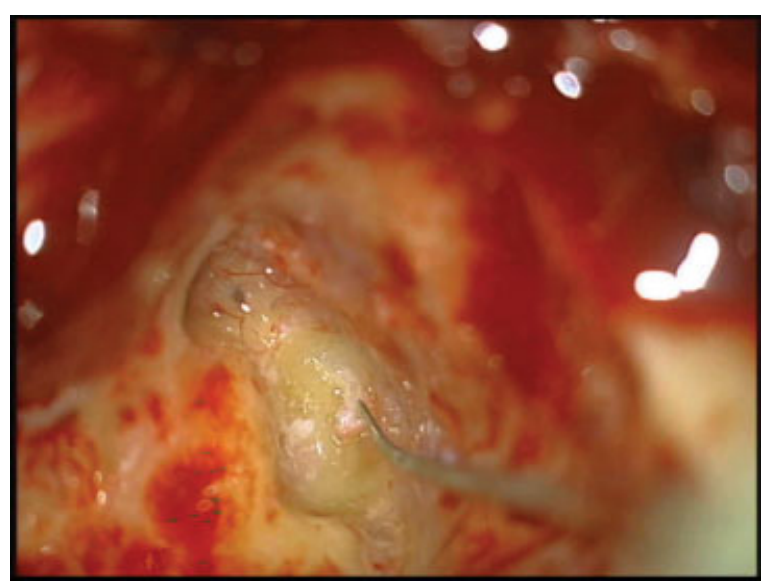

Figure 3 Intraoperative photo of fascia plugging the superior semicircular canal.

crus above the ampulla was first opened followed by the posterior crus. Care was taken to keep the endolymphatic membrane intact as fascia was pushed into the bony canal to obliterate it. While there was this minor variation in the

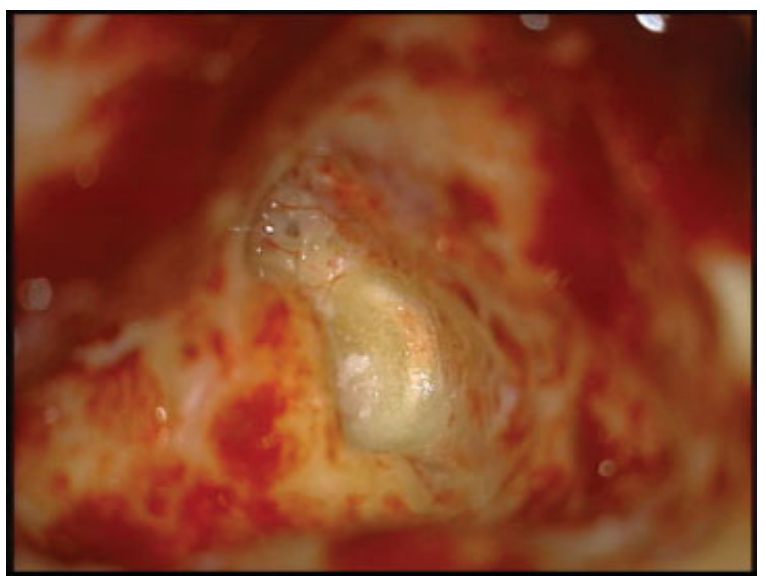

Figure 4 Intraoperative photo 3 demonstrating appearance of the superior semicircular canal after plugging. 
surgical technique, the emphasis was the complete occlusion of the canal lumen rather than the traditional resurfacing of the canal.

\section{Results}

A total of 10 cases with 11 operations are included in this case series. In this, one patient from Sint-Augustinus Hospital underwent bilateral transmastoid obliteration of the Sup SC. After the initial right-sided procedure, the patient had moderate improvement of his symptoms but because of the bilateral affliction of his disease, he insisted on having the procedure on the other side for further symptomatic management. The demographics and preoperative details of the patient are outlined in $\boldsymbol{- T a b l e} \mathbf{1}$. The average patient age was 46 years with a slightly higher number of female patients (60\% females vs. $40 \%$ males) and more left ears (70\%) compared with right ears (30\%) being operated on. Autophonia was the most frequently encountered symptom in this patient cohort. There was a wide range of hearing thresholds included in this case series including those with pseudo-conductive hearing loss.

- Table 2 details the postoperative findings of the patients included in this case series. Hearing preservation was achieved in all patients with the average change in the pure tone average between preoperative and postoperative audiograms being only $1 \mathrm{~dB}$. There were no significant complications from the procedures with only minor residual symptoms of imbalance and tinnitus in some patients. Follow-up in this series ranged from 3 to 12 months postoperatively.

All patients who required surgical management of Sup SC dehiscence underwent a transmastoid approach for canal plugging. Adequate access to Sup SC was achieved in all cases through a transmastoid approach. There were no cases that required a middle cranial fossa approach for revision or salvage.

\section{Discussion}

Sup SC dehiscence (SSCD) syndrome was first described by Minor et al in $1998 .{ }^{1}$ It is characterized by a constellation of vestibular and auditory symptoms, which includes pulsatile tinnitus, autophony, and vertigo. Examination findings may include vertigo that is noise induced (Tullio's phenomenon) or pressure induced (Hennebert sign)., ${ }^{3,5}$ The underlying mechanism of these symptoms relates to the third mobile window effect with dehiscence at the apical turn of Sup SC leading to loss of energy conducted to the cochlear and local vestibular disturbances. $^{2}$

The audiometry findings may include low-frequency conductive hearing loss on the affected side with intact acoustic reflexes which helps to differentiate SSCD from otosclerosis. ${ }^{2,4}$ Cervical vestibular evoked myogenic potentials (cVEMPs) are enhanced with reduced threshold on affected side, and tone burst cVEMP at $500 \mathrm{~Hz}$ can help to evaluate this condition. ${ }^{7}$ High-resolution computed tomography (CT) scan can visualize and define the bony dehiscence of the affected Sup SC. ${ }^{2}$

\begin{tabular}{|c|c|c|c|c|c|c|c|c|c|c|c|c|}
\hline \multirow{5}{*}{ 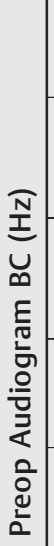 } & ঃ & 0 & $\stackrel{\mathrm{m}}{\mathrm{m}}$ & 은 & $\stackrel{\circ}{\circ}$ & 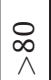 & เn & เn & $\stackrel{\circ}{\circ}$ & 은 & 0 & 0 \\
\hline & 용 & 0 & ○ & $\stackrel{\curvearrowright}{\sim}$ & in & $\stackrel{\circ}{\wedge}$ & $\stackrel{\sim}{\leftarrow}$ & 0 & $\stackrel{\curvearrowright}{\sim}$ & ๑ી & $\stackrel{\llcorner}{\sim}$ & $\stackrel{ }{\sim}$ \\
\hline & 옹 & 0 & $\stackrel{\llcorner}{\leftarrow}$ & $\stackrel{\text { ㄴ }}{\leftarrow}$ & in & 암 & $\stackrel{\circ}{\top}$ & in & in & $\stackrel{\bigcirc}{\sim}$ & $\stackrel{0}{1}$ & L \\
\hline & 오 & ᄂ & 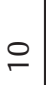 & $\stackrel{\sim}{\text { N }}$ & $\stackrel{\sim}{\sim}$ & เᄂ & $\stackrel{\circ}{\top}$ & $\frac{0}{1}$ & 0 & $\stackrel{2}{\longrightarrow}$ & in & เ \\
\hline & 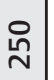 & $\stackrel{\circ}{\stackrel{1}{\prime}}$ & 으 & $\stackrel{\curvearrowright}{\sim}$ & in & 아 & $\stackrel{\circ}{1}$ & $\stackrel{0}{1}$ & 0 & 0 & $\stackrel{0}{1}$ & in \\
\hline \multirow{6}{*}{ 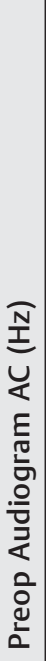 } & ○ & 0 & 아 & ○ & $\stackrel{\llcorner}{m}$ & 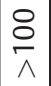 & $\stackrel{\circ}{\circ}$ & เి & 우 & $\begin{array}{l}\llcorner \\
\infty\end{array}$ & 0 & 0 \\
\hline & ঃ & 0 & 아 & 으ํ & $\stackrel{\llcorner}{\sim}$ & 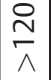 & 으 & 听 & 8 & প & $\stackrel{2}{\llcorner}$ & $\stackrel{\circ}{\sim}$ \\
\hline & 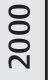 & เn & $\stackrel{\llcorner}{\sim}$ & $\stackrel{\curvearrowright}{\Upsilon}$ & $\stackrel{\llcorner}{\sim}$ & $\stackrel{ }{=}$ & $\stackrel{n}{\sim}$ & $\stackrel{\stackrel{\sim}{\sim}}{\sim}$ & 이 & 잇 & I & $\stackrel{\llcorner}{\sim}$ \\
\hline & 응 & เn & $\stackrel{\mathrm{m}}{\mathrm{m}}$ & $\stackrel{\text { 늠 }}{\longrightarrow}$ & $\stackrel{\llcorner}{m}$ & ஜே & $\stackrel{\stackrel{\sim}{\sim}}{\sim}$ & $\stackrel{\stackrel{n}{m}}{m}$ & 유 & $\stackrel{\operatorname{Ln}}{\sim}$ & $\stackrel{n}{\leftarrow}$ & 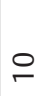 \\
\hline & 으 & 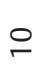 & $\stackrel{\llcorner}{\sim}$ & $\stackrel{N}{ }$ & 유 & 능 & $\stackrel{2}{\leftarrow}$ & เก & 으 & 우 & $\stackrel{\llcorner}{\sim}$ & $\stackrel{\llcorner}{\sim}$ \\
\hline & $\stackrel{\circ}{\stackrel{n}{N}}$ & 으 & $\stackrel{m}{.}$ & $\stackrel{\sim}{\sim}$ & $\stackrel{\text { ำ }}{+}$ & $\stackrel{\llcorner}{\infty}$ & $\stackrel{\curvearrowright}{\curvearrowright}$ & เ & ถู & $\stackrel{\mathrm{m}}{\mathrm{s}}$ & $\stackrel{\llcorner}{\sim}$ & $\stackrel{\llcorner}{\sim}$ \\
\hline $\begin{array}{l}\frac{1}{2} \\
\frac{0}{2} \\
\frac{0}{2} \\
0\end{array}$ & & $\wedge$ & $\lesssim$ & $\stackrel{\infty}{\leftarrow}$ & $\hat{m}$ & $\stackrel{\infty}{\sigma}$ & $\stackrel{\infty}{\square}$ & $\stackrel{\infty}{m}$ & ๓n & กิ & $\stackrel{\sim}{\sim}$ & $\approx$ \\
\hline 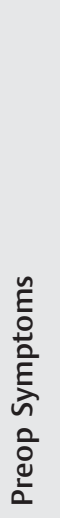 & & 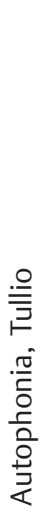 & 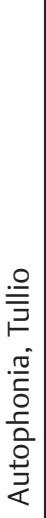 & 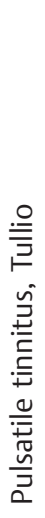 & 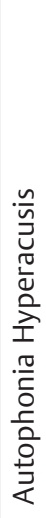 & 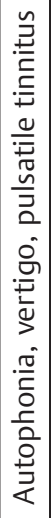 & 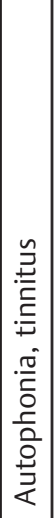 & 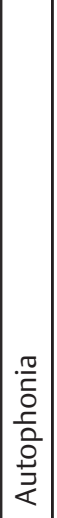 & 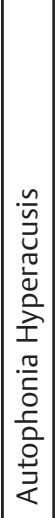 & 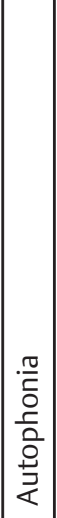 & 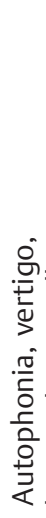 & 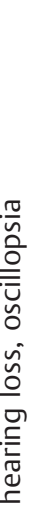 \\
\hline$\frac{0}{i n}$ & & - & - & - & $\propto$ & $\propto$ & $\simeq$ & -1 & - & - & $\propto$ & - \\
\hline$\stackrel{\times}{\sim}$ & & 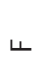 & $\sqcup$ & $\Sigma$ & 4 & $\Sigma$ & ப & $\sqcup$ & 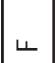 & $\Sigma$ & $\Sigma$ & $\Sigma$ \\
\hline 㲾 & & $\stackrel{m}{m}$ & 守 & ถิ & กิ & $\stackrel{0}{1}$ & ஏ & $\overline{\text { กn }}$ & $\stackrel{\infty}{+}$ & $\stackrel{n}{N}$ & $\bar{m}$ & $\bar{m}$ \\
\hline$\ddot{\alpha}$ & & - & $\sim$ & $m$ & $\nabla$ & in & 0 & 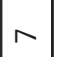 & $\infty$ & a & $\stackrel{\circ}{\circ}$ & 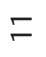 \\
\hline
\end{tabular}




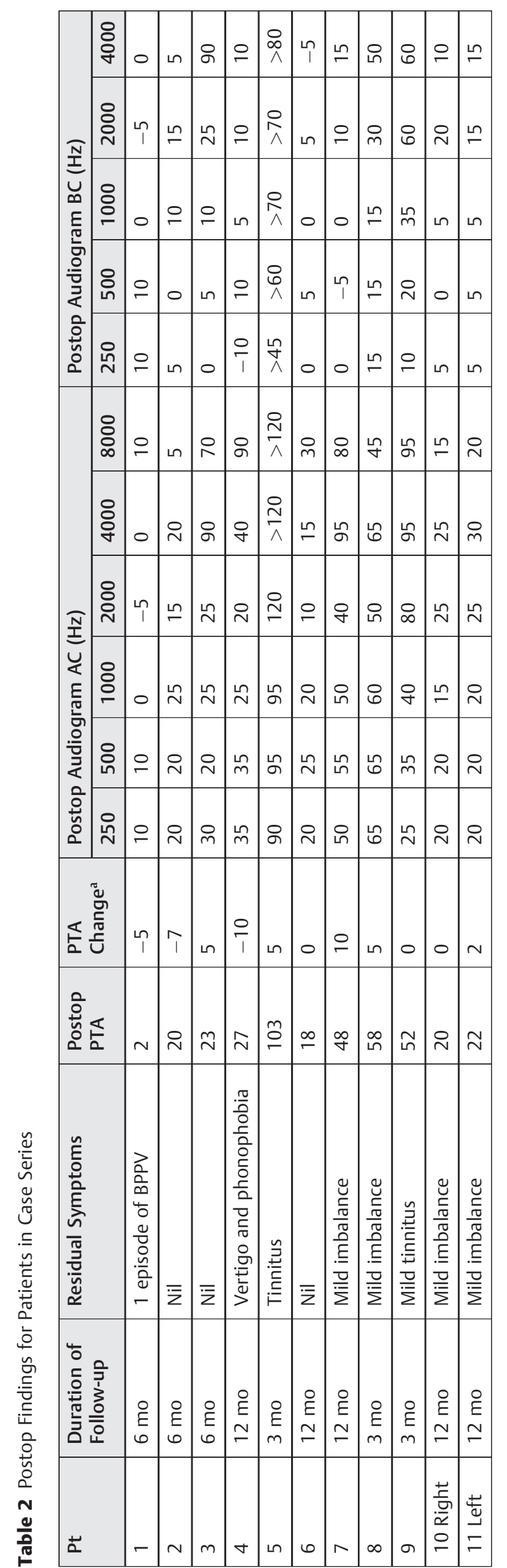

Surgical treatment of SSCD is usually reserved for patients with debilitating symptoms. The traditional surgical approach was a middle cranial fossa approach with resurfacing of the dehiscence with fascia or bone graft. However, in a recent meta-analysis, it was found that resurfacing had higher failure and recurrence rates compared with canal plugging. ${ }^{6} \mathrm{~A}$ middle cranial fossa approach is also associated with the morbidity of a craniotomy and temporal lobe retraction. Some authors have also argued that traumatic manipulation or inadvertent suctioning of the membranous labyrinthine and loss of perilymph during dural elevation may contribute toward postoperative sensorineural hearing loss ${ }^{5}$ which has been reported in case series to be as high as $30 \%{ }^{8}$ As the focus of surgical repair shifts away from canal resurfacing to canal plugging, the transmastoid approach has gained prominence.

Several case series of the transmastoid approach to canal plugging have been described in the literature. ${ }^{4,5,9,10}$ It was first described by Brantberg et al where they described occlusion of the canal via four separate fenestrations although one of the two patients described suffered sensorineural hearing loss. ${ }^{9}$ Subsequently, Agrawal and Parnes described a modification with only two fenestrations on either side of the dehiscence followed by repair of middle fossa defect with fascia with good results. Kirtane et al in 2009 described a technique of plugging through the dehiscence using a transmastoid approach with dural elevation. ${ }^{10}$ In this case series, we present results using both single fenestration as well as double fenestration techniques which appear to produce similar results. We believe the single fenestration of Sup SC is likely to produce similar results without the risk of injury to the other semicircular canal during the exposure and can be performed with minimal dural manipulation. Regardless of the number of fenestrations, the key to success we believe is the plugging of Sup SC via fenestration rather than dural elevation and resurfacing the canal.

One key element critical to the success of this transmastoid approach is the degree of temporal bone pneumatization. While there have been numerous studies assessing temporal bone pneumatization, the use of CT scans with three-dimensional reconstruction has made volumetric assessment of the temporal bone possible. ${ }^{11}$ While this approach is helpful in assessing overall pneumatization of temporal bones, it is the degree of dural overhang and slope of the tegmen that is of most interest in a transmastoid approach to canal plugging, as this determines the degree of dural manipulation required to access the Sup SC. In a recent anatomical analysis of tegmen slopes and shapes, only $3.8 \%$ of the study population had a flat tegmen with majority of patients $(92.4 \%)$ having a slight overhang of the dura laterally before sloping superiorly as the dura continues medially. ${ }^{12}$ The implication is that while there may be overhang of dura laterally, as the surgeon continues medially to approach the Sup SC, the dura slops away providing access to the Sup SC. By using bipolar coagulation to shrink the dura, the lateral dural overhang can also be gently elevated, although dural elevation medially should be avoided to prevent disruption of the membranous labyrinth. One of the advantages of canal plugging compared with canal resurfacing technique is that with a canal plugging and a 
single fenestration technique, only the inferior-lateral aspect of the apex of the Sup SC arch needs to be exposed. This means much less dural manipulation and elevation is necessary to achieve the same exposure. In our case series, all patients were able to be treated via this approach with none requiring a middle cranial fossa approach for salvage.

A variety of materials have been used to plug the semicircular canal, we prefer the use of fascia as well as bone pâté mixed with Fibrin Glue (Tisseel) to seal and occlude the canal. The use of these materials has been supported in animal studies where bone pâté was found to have the best hearing outcome and most periosteal osteoneogenesis at the occlusion site compared with bone wax and muscle. ${ }^{13}$

In this case series, excellent hearing preservation has been achieved in both institutions with no significant change in the pure tone average postoperatively. In terms of symptom control, the majority of patients had excellent relief of their auditory and vestibular symptoms although some had mild residual imbalance. One patient required bilateral procedures to obtain total symptom control. It should be remembered that surgery for SSCD is usually reserved for those with debilitating vestibular symptoms with the aim of treatment to alleviate the vestibular symptoms while preserving the underlying hearing. In that respect, the transmastoid approach to plugging of the Sup SC allows occlusion of the canal without the morbidity of a craniotomy and provides excellent postoperative results. However, this is a relatively rare condition where the numbers of cases presented are small and follow-up has been relatively short. Further research is required to definitively investigate the long-term results and potential complications of this approach.

\section{Conclusion}

While SSCDS is a rare condition, it can cause debilitating symptoms. The traditional surgical approach in treating this condition is a middle cranial fossa approach with resurfacing of the Sup SC. This multi-institutional case series demonstrates the safety as well as the efficacy of the transmastoid approach to plugging of the Sup SC. Our result suggests an alleviation of the auditory and vestibular symptoms as well as preservation of sensorineural hearing without the morbidity associated with a craniotomy. Regardless of whether a single or double fenestration is used to occlude the canal, the key is that occlusion rather than resurfacing of the Sup SC is effec- tive in controlling the symptoms. Where there is sufficient access to plug the canal via a transmastoid approach, it is difficult to justify the potential additional morbidity of a middle fossa extradural approach to treat this condition.

\section{References}

1 Minor LB, Solomon D, Zinreich JS, Zee DS. Sound- and/or pressureinduced vertigo due to bone dehiscence of the superior semicircular canal. Arch Otolaryngol Head Neck Surg 1998;124(3): 249-258

2 Minor LB, Carey JP, Cremer PD, Lustig LR, Streubel S-O, Ruckenstein MJ. Dehiscence of bone overlying the superior canal as a cause of apparent conductive hearing loss. Otol Neurotol 2003;24(2): 270-278

3 Minor LB. Clinical manifestations of superior semicircular canal dehiscence. Laryngoscope 2005;115(10):1717-1727

4 Agrawal SK, Parnes LS. Transmastoid superior semicircular canal occlusion. Otol Neurotol 2008;29(3):363-367

5 Deschenes GR, Hsu DP, Megerian CA. Outpatient repair of superior semicircular canal dehiscence via the transmastoid approach. Laryngoscope 2009;119(9):1765-1769

6 Vlastarakos PV, Proikas K, Tavoulari E, Kikidis D, Maragoudakis P, Nikolopoulos TP. Efficacy assessment and complications of surgical management for superior semicircular canal dehiscence: a metaanalysis of published interventional studies. Eur Arch Otorhinolaryngol 2009;266(2):177-186

7 Roditi RE, Eppsteiner RW, Sauter TB, Lee DJ. Cervical vestibular evoked myogenic potentials (cVEMPs) in patients with superior canal dehiscence syndrome (SCDS). Otolaryngol Head Neck Surg 2009;141(1):24-28

8 Mikulec AA, Poe DS, McKenna MJ. Operative management of superior semicircular canal dehiscence. Laryngoscope 2005;115 (3):501-507

9 Brantberg K, Bergenius J, Mendel L, Witt H, Tribukait A, Ygge J. Symptoms, findings and treatment in patients with dehiscence of the superior semicircular canal. Acta Otolaryngol 2001;121(1): 68-75

10 Kirtane MV, Sharma A, Satwalekar D. Transmastoid repair of superior semicircular canal dehiscence. J Laryngol Otol 2009; 123(3):356-358

11 Han SJ, Song MH, Kim J, Lee WS, Lee HK. Classification of temporal bone pneumatization based on sigmoid sinus using computed tomography. Clin Radiol 2007;62(11):1110-1118

12 Makki FM, Amoodi HA, van Wijhe RG, Bance M. Anatomic analysis of the mastoid tegmen: slopes and tegmen shape variances. Otol Neurotol 2011;32(4):581-588

$13 \mathrm{Kim}$ TH, Nam BH, Park CI. Histologic changes of lateral semicircular canal after transection and occlusion with various materials in chinchillas. Korean J Otolaryngol Head Neck Surg 2002;45(4): 318-321 